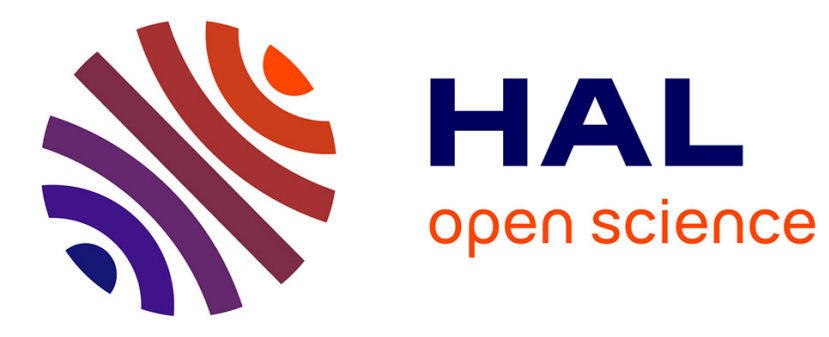

\title{
Projective meaning and attachment
}

Jacques Jayez

\section{To cite this version:}

Jacques Jayez. Projective meaning and attachment. Maria Aloni, Harald Bastiaanse, Tikitu de Jager \& Katrin Schulz. Logic, Language and Meaning. Revised Selected Papers of the 17th Amsterdam Colloquium, Amsterdam 2009, LNAI 6042, Springer, pp.325-334, 2010, Lecture Notes in Artificial Intelligence. hal-01073506

\section{HAL Id: hal-01073506 https://hal.science/hal-01073506}

Submitted on 9 Oct 2014

HAL is a multi-disciplinary open access archive for the deposit and dissemination of scientific research documents, whether they are published or not. The documents may come from teaching and research institutions in France or abroad, or from public or private research centers.
L'archive ouverte pluridisciplinaire HAL, est destinée au dépôt et à la diffusion de documents scientifiques de niveau recherche, publiés ou non, émanant des établissements d'enseignement et de recherche français ou étrangers, des laboratoires publics ou privés. 


\title{
Projective Meaning and Attachment
}

\author{
Jacques Jayez \\ ENS de Lyon and $\mathrm{LSC}_{2}$, CNRS, Lyon France
}

\begin{abstract}
This paper examines the possibility of providing a unified account of the projection properties of presuppositions, conventional and conversational implicatures. I discuss the solution offered in (Roberts et al. 2009) and show that the central notion we need to cover the spectrum of observations is that of attachment.
\end{abstract}

\section{Introduction}

The most basic observations about presuppositions concern what is called their projection behaviour. Roughly speaking, a presupposition can be characterised as an entailment which is able to project. A sentence $\mathrm{S}$ presupposes a proposition $\phi$ whenever S entails $\phi$ and certain 'suitably modified' versions of S entail $\phi$ (projection). The 'suitably modified' qualification encompasses negation, interrogation and a variety of embeddings. For instance, Mary knows that Paul cheated on the exam and its modified versions Mary does not know / Does Mary know that Paul cheated on the exam preserve the presupposition that Paul cheated.

Projection is not automatic. It depends on context and on the properties of embedding. A less well-known property concerns the limitations on attachment. Ducrot (1972) had noted that it is difficult to attach a discourse constituent to a presupposition. For instance, the only possible meaning of (1) is that Paul does not cheat (asserted content) because he was behind in his work. The probably more natural interpretation that Paul was in the habit of cheating (presupposed content) because he was always behind cannot be construed.

(1) Paul has stopped cheating on exams because he was always behind in his work

The question naturally arises whether these two properties can be unified in some way and perhaps ultimately viewed as two sides of the same coin. In the next section, I describe in more detail the symmetry between projection and attachment constraints. In section 3, I present the approach of Roberts et al. (2009) and highlight the possibility of deriving from it attachment constraints, which are shown to have a clear experimental reflection in section 3.2. Finally, in section 4, I show that attachment is a more fundamental notion to analyse the interaction between discourse and projection. 


\section{Extending the Symmetry between projection and attachment}

There is little doubt that presuppositions tend to project and do not provide a natural attachment site. Roberts et al. (2009) suggest that projection extends to conventional implicatures (CIs) and to certain conversational implicatures (cis). For instance, they borrow from Chierchia and McConnell-Ginet the observation that non-restrictive relative clauses project. (2) would be a case of CI projection because (i) it entails that Paul cheated on the exam and (ii) according to Potts (2005), such clauses trigger a CI.

(2) a. Paul, who has cheated on the exam, might be dismissed

b. Do you think that Paul, who has cheated on the exam, might be dismissed?

Cases of ci projection have been discussed in particular in (Simons 2005). Consider (3) (Simon's example 27). Answer B1 makes sense only if one assumes some sort of negative connection between rain and going on a picnic. This connection is preserved in $\mathrm{B} 2$ variants.

(3) A - Are we going on a picnic?

B1 -It's raining

B2 -It's not raining / Is it raining?

Attachment limitations have also been investigated with a similar result. Ducrot's (1972) loi d'enchaînement ('linking law') targets presuppositions. In a nutshell, the linking law forbids any attachment to a presupposition, whether by way of a subordinating or coordinating conjunction, except for et ('and') and si ('if'), or by way of a 'logical relation'. In (Jayez 2005, Jayez and Tovena 2008), it is claimed that conventional implicatures are subject to the same limitations. For instance, in (4), the preferred interpretation is that John being unable to register for the next term is the cause of his failure. A more natural interpretation is that it is bad luck for him since he cannot register, but constructing this interpretation would involve recruiting the CI trigger unfortunately for the attachment (see Potts 2005 for evaluative adverbs and Jayez and Rossari 2004 for parentheticals).

(4) Unfortunately, Paul has failed his exam, because he cannot register for the next term

Finally, it has been noted in various works that CIs cannot provide natural targets for refutation, see (Jayez and Rossari 2004, Potts 2005). E.g. the refutations in (5) target only the asserted proposition that Paul has failed his exam, leaving aside the evaluative CI trigger unexpectedly.

(5) A - Paul has unexpectedly failed his exam

B - You lie / You are wrong / Impossible / Quite the contrary 
I consider that refutation cases fall into the category of attachment limitations. In a refutation, the attempt by an addressee to attach a new constituent to a presupposition or to an implicature is bound to be perceived as artificial.

It is of course tempting to hypothesize that there is a common source behind the projection and the attachment observations, and that presuppositions, CIs and cis can be grouped into a natural class, whose members differ essentially by specific lexical profiles.

\section{Accounting for the Symmetry: the QUD Approach}

\subsection{Basics}

Recently, Roberts et al. (2009) have proposed that presuppositions, CIs and cis, which they group under the generic term of not-at-issue content, after Potts' term for CIs, share indeed a central property: they do not necessarily address the Question Under Discussion (QUD). Assuming that each discourse is organised around at least one common topic (the QUD), they offer the following principle.

(6) QUD principle All and only the not-at-issue content may project.

Two important points are to be mentioned at this stage. First, if we decide to see presuppositions and implicatures as members of a common family, it is no longer possible to attribute their common behaviour to properties that do not hold for the whole class. So, anaphoric or dynamic theories of presuppositions, whatever their merits, are not plausible candidates for unifying presuppositions, CIs and cis since, for instance, they do not make room for CIs (Potts 2005). Roberts et al. make the same point for common ground theories of presuppositions.

Second, if the QUD theory is correct, it should allow one to derive the attachment properties. Roberts et al. include the refutation test among those properties that characterise the projecting elements but they do not tackle the general question of attachments. Generalising from Potts, I assume that the semantic and pragmatic contribution of a discourse constituent can be seen as a $n$-tuple $\left\langle q, a_{1} \ldots a_{n}\right\rangle$, where the first element (at-issue content) addresses the QUD and the other ones are presupposed or implied material. Functions can extract the relevant material. If $C$ is a constituent, $A I(C)$ extracts the at-issue content of $C$, $\operatorname{pres}(C)$ the presuppositions, etc. Consider now a pair of adjacent constituents $\left(C_{1}, C_{2}\right)$ in a monologue, typically two successive sentences or clauses that convey a proposition. By using $C_{1}$, the speaker signals that she contributes to the QUD with $A I\left(C_{1}\right)$. If the next constituent is connected to an element of $C_{1}$ different from $A I\left(C_{1}\right)$, the speaker abandons the QUD. In most contexts, this is an odd move because the speaker just addressed the QUD via $A I\left(C_{1}\right)$, hence the impression of a non sequitur. In dialogues, the situation is a little different since we cannot, in general, assign to participants a unique discourse strategy. It may be the case that participants disagree on certain issues. This accounts for the fact, noted by Jayez and Rossari and von Fintel (2004), that it is perfectly possible to interrupt the discourse trajectory ascribed to a participant, for instance by questioning a presupposition or a CI she endorses. 
(7) A - Unfortunately, Paul has failed his exam

B - Well, I wouldn't call that 'unfortunate' / It's not really unfortunate, you know, he's so lazy. He got what he deserves

In monologues, the price to pay for abandoning the QUD is higher since the speaker is supposed to have a coherent strategy. This is not quite impossible, however. A speaker may signal explicitly that she is abandoning the QUD with a special discourse marker such as by the way. In that case, the speaker may sound uncooperative, especially if she abruptly shifts the topic in the middle of a serious discussion, but she is not incoherent since she makes clear that she is not currently following a plan to tackle the QUD (8).

(8) Paul stopped smoking. By the way, Mary never took to smoking

There is also the (important) possibility that the non-at-issue content does address the QUD, a point to which I will return in section 4.2. In (9), B uses the double fact that Paul has been smoking and that he does not smoke as an argument in favour of her conclusion that Paul has a strong will.

(9) A - Does Paul have a strong will?

B - Generally speaking, yes. He has stopped smoking, for instance

\subsection{Simple Experimental Evidence}

One might argue that the QUD hypothesis, in its current stage, is only a clever guess. However, preliminary experimental evidence is clearly consonant with the hypothesis. If the QUD approach is right, competent speakers should process more easily an attachment to the at-issue content than to the non-at-issue content. In order to evaluate this prediction, I carried out a simple categorisation experiment.

46 French students were asked to classify 40 French two-sentence pairs as either banale (ordinary) or bizarre (weird). They were all native speakers, with an age range of 17-27 and an age mean of 20.1. The test was administered collectively (all the subjects rated the pairs together). Subjects had to read and rate pairs following the order on the test sheet and were not allowed to correct a previous choice. They were asked to run through the pair list as fast as possible. In each pair that was not a filler, the sentences were related by a consequence discourse marker (donc or alors $\approx$ 'so', 'therefore') or by a causal/justification subordinating conjunction (parce que $\approx$ 'because' or puisque $\approx$ 'since'). The pairs exploited either an at-issue or a non-at-issue linking and featured a presupposition or conventional implicature trigger in a $2 \times 2$ design. The following table shows the translations of the first five pairs with the expected answer in the last column. 


\begin{tabular}{|l|l|l|l|l|}
\hline filler & trigger & connection mode & text & expected answer \\
\hline yes & & & Max had the flu, so he stayed at home & OK \\
\hline yes & & & Luc likes jam because the weather is fine & weird \\
\hline no & almost & at-issue & Mary is almost late, so she hurries up & OK \\
\hline no & stop & non at-issue & Paul stopped quivering, so he was cold & weird \\
\hline no & unfortunately & non at-issue & $\begin{array}{l}\text { The weather was fine, so, unfortunately, } \\
\text { Susan had work to do }\end{array}$ & weird \\
\hline
\end{tabular}

The results can be analysed in several ways. In this paper, I describe only an exploration based on the Mac Nemar test for paired samples. This test is usually applied to temporal transitions of the same sample of subjects. For instance one wants to determine whether the proportion change in the value of some variable before and after a medical treatment is significant. The test can in fact be used whenever the proportions of binary responses of the same group are to be compared in two different conditions, namely two types of sentence pairs in our case. The sentence pairs (excluding fillers) were classified into different categories, according to their connection mode (at-issue or not at-issue) and the presupposition or CI triggers they contained. They were compared pairwise and the 496 resulting tests were themselves classified into different categories according (i) which mode of connection (at-issue, not at-issue with presupposition, not at-issue with CI) each pair exhibited and (ii) whether the trigger was identical in the two pairs.

The most salient observation is that, for identical triggers, there is more often a significant difference between the at-issue and non-at-issue cases and subjects preferentially reject the non-at-issue variant. There are 10 pairs (out of 13) that show a significant difference in the at-issue vs. (non-at-issue and presuppositional) comparison, and 15 pairs (out of 16) for the at-issue vs. (non-at-issue and CI) comparison. This is in agreement with the QUD approach and also with the extended version of Ducrot's loi d'enchaînement. However, individual results suggest that the difference in accessibility between at-issue and non-atissue content may vary across triggers. For instance, the seul ('only') and the $\grave{a}$ peine ('hardly') element do not fit well into this general picture. More work is needed to evaluate the import of specific properties of lexical items.

\section{The attachment approach}

In spite of its attractiveness, the QUD approach faces some problems and I will defend the view that the notion of attachment is a better candidate to address them.

\subsection{When Contrast Steps in}

The possibility of linking depends, among other things, on the discourse relation on which the linking is based. Ducrot's prohibition can be extended to conventional implicatures but concerns primarily what he called argumentative relations, that is, essentially, justification or explanation and consequence. The experimental findings reported above are based on those very same relations. 
Contrast discourse markers do not give so clear-cut results. For instance, under at least one interpretation, B's answer in (10) means that, in contrast to Mary having smoked, Paul never smoked. Crucially, the at-issue content must be ignored in the contrast for it to make sense (see ?? Mary does not smoke but Paul never smoked). Many analogous examples can be constructed: in (11) the linking associates the presupposition that Mary got three A's and the fact that she failed the French exam. In (12) the implicature that Mary is under twenty is involved (Jayez and Tovena 2008).

(10) A - Do your friends smoke, in general?

B - It depends. Mary has stopped smoking but Paul never smoked

(11) A - How did Mary fare?

B - It depends. She was the only one to get three A's but she failed the French exam

(12) A - How old are they?

B - Mary is almost twenty but Paul is well over twenty

Following Umbach (2005), I assume that, in such cases, but triggers the accommodation of a quaestio, that is, an overt or abductively reconstructed question with respect to which the contrastive discourse constitutes a relevant answer. But dually connects two alternatives by asserting one and negating the other (the confirm + deny condition in Umbach's terms). A typical quaestio for $p$ but $p^{\prime}$ is 'are $p$ and $\neg p^{\prime}$ both true?'. Let us compare now (13), (14) and (15). B's answer in (13) is predictably odd since its at-issue content bypasses the QUD (whether Mary has been smoking in the past). In (14), the at-issue content of the first conjunct still bypasses the QUD, since the proposition that Mary does not smoke is hardly relevant to A's question. However, the combination of the presupposed part (Mary has been smoking) and the at-issue content of the second conjunct addresses the quaestio made explicit through A's question. (15) shows that the order of conjuncts matters. Why is it so?

$$
\begin{aligned}
& \text { A - Did Mary smoke? } \\
& \text { B - ??Mary has stopped smoking }
\end{aligned}
$$

$$
\begin{aligned}
& \text { A - Did both Mary and Paul smoke? } \\
& \text { B - Mary has stopped smoking, but Paul never smoked }
\end{aligned}
$$

A - Did both Mary and Paul smoke?

B - ??Paul never smoked, but Mary still smokes

If the two conjuncts were conceived of as independent, as in an update sequence, the (14)-(15) contrast would be mysterious. I propose to represent the structures studied by Umbach as complex propositions, where the second conjunct 'maximally settles' the issue, from the speaker's point of view, that is, expresses the ultimate piece of information the speaker delivers on this particular issue at this stage. The asymmetry between the two conjuncts is captured by saying that (i) the second conjunct is attached to a new quaestio by a Question-Answer discourse relation in the most explicit cases or by a more abstract relation of 
Resolution and (ii) the new quaestio takes into account the partial resolution of the initial quaestio by the first conjunct.

(16) Given a quaestio $Q$, an Umbach-structure $p$ but $p^{\prime}$ results in a Resolution type attachment of $p^{\prime}$ to the quaestio $Q^{\prime}$ obtained by eliminating the alternatives compatible with $Q$ but incompatible with $p$.

(16) captures the idea that the second conjunct is the salient resolver. If we accept that, whenever the quaestio remains implicit it is nonetheless a particular form of QUD, possibly one only the speaker is initially privy to (see Ginzburg 2009 for the epistemic treatment of QUDs), we see that the QUD intuition can be preserved in the above cases but that one has to introduce some additional attachment structure. The proposition that the speaker communicates to settle the issue raised by the QUD must depend on the at-issue content of the attached resolver. This requirement is violated in (15) because the second conjunct, that maximally settles the quaestio by selecting the alternative 'Mary smoked', does not address the new quaestio 'Granted that Paul did not smoke, did Mary smoke?' through its at-issue content.

\subsection{The QUD Principle Revised}

The problem discussed in this section is more serious. Consider (17).

$$
\begin{aligned}
& \text { A - Is Paul a good partner? } \\
& \text { B - He does not answer to mails very quickly }
\end{aligned}
$$

The preferred interpretation of B's answer is that Paul answers to mails, but not very quickly. Thus, the proposition that Paul answers to mails survives the negation and projects. However, it is difficult to say that it does not address the QUD, at least not if we consider what is relevant to the topic made salient by A's question. Similar observations hold for standard presuppositional cases. B's answer in (18) clearly presupposes that John has been smoking and this fact is strongly relevant to the main topic of John's temperament. It suggests for instance that John was unable to put a term to his addiction.

$$
\begin{aligned}
& \text { A - Does Paul have a strong will? } \\
& \text { B - Generally speaking, no. He didn't stop smoking, for instance }
\end{aligned}
$$

Note that neither with (17) nor with (18) do we base our understanding only on a general or circumstantial rule like [addiction $\sim$ no strong will]. It is necessary to make the fact that Paul answers to mails or that he has smoked enter the picture, in order to draw from B's answers various inferences relevant to the QUD. So, the situation cannot be reduced to the Simon's type of example we mentioned in section 2 .

(17) and (18) illustrate the possibility that information pieces which address the QUD project. Crucially, in both cases, one observes attachment limitations. E.g. it is impossible to interpret (19a) and (19b) as meaning that Paul answers to mails because he is professional and that he smoked because he liked smoking. 
(19) a. ...He does not answer to mails very quickly, because he is very professional

b. ...He didn't stop smoking, for instance, because he liked that

Such observations have two consequences. First, they show that material usually considered as implied or presupposed can address the QUD and be projected. Second, if attachment limitations were a reflection of not addressing the QUD, as I have proposed, they should disappear. In view of these problems, I propose to modify principle (6) as follows.

(20) Revised QUD principle In linguistic communication, whenever some content is conventionally marked as obligatorily interpretable with respect to the QUD, all and only the content that is not marked in this way projects.

(20) postulates that every piece of linguistic communication can come with conventionally QUD-relative content. The linguistic marking of at-issue content vs. presuppositions or CIs provides a typical case. I leave open the possibility that a linguistic item contains no conventionally QUD-relative content, as might be the case for interjections (Wharton 2003). Conventional QUD-relative content does not necessarily address the QUD, but is conventionally marked as obligatorily interpretable with respect to it. Thus, an uncooperative conventionally QUDrelative discourse constituent which abruptly 'drops' the current topic cannot be projected.

Conventionally QUD-relative content contains those elements which contribute to 'what is said' in the Gricean sense, that is, all the non-presupposed and non-conventionally implied formulae resulting from exploiting the linguistic code and assigning values to those indexical arguments that occur in the predicates of such formulae. This amounts to saying that the conventionally QUD-relative content comprises entailments and certain explicatures ${ }^{1}$ (Sperber and Wilson 1986). For instance, in (21a) the QUD relative content includes all the entailments of the proposition that it is raining at $t$, where $t$ is the value assigned to the time indexical associated with the sentence tense. In contrast, whereas the existence of a consequence relation between the rain and staying at home in (21b) is also considered as an explicature in some recent approaches (see Ariel 2008 for a survey), it is not integrated into the QUD-relative content under the present analysis. This choice is motivated in the next section, which considers the attachment problem.

(21) a. It is raining

b. It is raining, so I prefer to stay at home

\footnotetext{
${ }^{1}$ Standard explicatures result from interpreting pronouns and providing spatiotemporal coordinates.
} 


\subsection{Attachment Revisited}

The reviewed data suggest that attachment is not uniquely context-sensitive. In fact, for at least certain discourse relations, including Explanation, Justification and Contrast, attachment may not target non QUD-relative content, even when this content happens to address the QUD, see (17), (18) and (19). This is not to be confused with a prohibition on binding. Lexical material such as pronouns or additive discourse markers (see Winterstein 2009 for too) can be bounded to non QUD-relative content. I propose that attachment limitations are related to the independence of QUD-relative and non QUD-relative content. Consider the well-known 'sister' example discussed by Stalnaker.

(22) I have to pick up my sister at the airport

In a DRT-based treatment (Geurts 1999), (22) asserts that the speaker S has to pick up $x$ at the airport and presupposes that $x$ is a sister of the speaker. The net

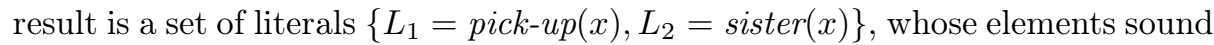
unrelated. For instance, there is no obvious 'proposition' (literal) that would be a common consequence of $L_{1}$ and $L_{2}$ or would entail jointly $L_{1}$ and $L_{2}$. More generally, given the contribution of a discourse constituent, $\left\langle L_{1}, \ldots, L_{n}\right\rangle$, there is no guarantee that $L_{1} \ldots L_{n}$ can be jointly connected to a common literal through some discourse relation. If attachment was unconstrained, the general independence of the contribution members would make the construction of an interpretation in discourse even more difficult than it is. For instance, given simple two sentence dialogues of the form (A:S1= $\left.\left\langle L_{1}, L_{2}\right\rangle-\mathrm{B}: \mathrm{S} 2=\left\langle L_{1}^{\prime}, L_{2}^{\prime}\right\rangle\right)$, A would have to eliminate one of $L_{1}^{\prime}, L_{2}^{\prime}$ since both would be a priori equivalent candidates for providing a continuation to S1. Symmetrically, B would have to eliminate one of $L_{1}, L_{2}$ to determine which part of the contribution is intended by $\mathrm{A}$ to require a continuation. This would lead to massive ambiguity in the worst cases. A plausible conjecture is that languages have developed conventionalised preferences for attachment in order to streamline discourse management. We are now in a better position to understand the relation between the QUD and attachment. Only those elements that are marked for attachment are obligatorily interpreted as addressing the QUD because the constraints on attachment help keeping the thread in discourse evolution. Accordingly, when an element is marked for attachment, it is also marked as contributing to the discourse topic at the current point. Elements that are not so marked can project, since they are subtracted from the current discussion thread. As we saw in the previous section, this does not prevent something from addressing the QUD and projecting, if this element is not conventionally marked as attachable (and addressing the QUD).

\section{Conclusion}

The upshot of the previous discussion is that an element can address the QUD and nonetheless project. This is so because projection is (negatively) associated with conventionalised attachment preferences, that do not vary with the 
context. Several important issues are still pending. I will mention two of them. First, additional experimental work is necessary to construct models of cognitive processing for non-at-issue content. In particular, recent work on anticipatory effects (Chambers and San Juan 2008) might complicate the debate over the role of common ground and, more generally, the dynamic character of presuppositions, questioned in various approaches (Abbott, Schlenker). Second, the status of non-conventional elements, so called 'conversational implicatures', is unclear. Since they do not necessarily correspond to a segment of linguistic code, their integration into a layered conventional system, as is proposed here, has to be reconsidered.

\section{References}

Ariel, M. (2008). Pragmatics and Grammar. Cambridge University Press, Cambridge (UK).

Chambers, C.G. and San Juan, V. (2008). Perception and Presupposition in Real-Time Language Comprehension: Insights from Anticipatory Processing. Cognition 108, 26-50.

Ducrot, O. (1972). Dire et ne pas Dire. Hermann, Paris.

von Fintel, K. (2004). Would you Believe it? The king of France is Back! Presuppositions and Truth-Value Intuitions. In Reimer, M. and Bezuidenhout, A. (eds.), Descriptions and Beyond. Oxford University Press, Oxford.

Geurts, B. 1999. Presuppositions and Pronouns. Elsevier, Amsterdam.

Ginzburg, Jonathan (2009). The Interactive Stance: Meaning for Conversation. CSLI Publications, Stanford, to appear.

Jayez, J. (2005). How Many are 'several'? Argumentation, Meaning and Layers. Belgian Journal of Linguistics 19, 187-209.

Jayez, J. and Rossari, C. (2004) Parentheticals as Conventional Implicatures. In Corblin, F. and de Swart, H. (eds.), Handbook of French Semantics, CSLI Publications, Stanford, 211-229.

Jayez, J. and Tovena, L. (2008) Presque and Almost : How Argumentation Derives from Comparative Meaning. In Bonami, O. and Cabredo Hofherr, P. (eds.), Empirical Issues in Syntax and Semantics 7, 217-240.

Potts, C. (2005). The Logic of Conventional Implicatures. Oxford University Press, Oxford.

Roberts, C., Simons, M., Beaver, D. and Tonhauser, J. (2009). Presuppositions, Conventional Implicatures and beyond: A Unified Account of Projection. Proceedings of the ESSLLI 2009 Workshop New Directions in the Theory of Presupposition.

Simons, M. (2005). Presupposition and Relevance. In Szabo, Z.G. (ed.), Semantics vs. Pragmatics, Oxford University Press, Oxford, 329-355.

Sperber, D. and Wilson, D. (1986). Relevance. Communication and Cognition. Blackwell, Oxford.

Umbach, C. (2005). Contrast and Information Structure: A Focus-Based Analysis of But. Linguistics 43, 207-232.

Wharton, Tim (2003). Interjections, Language, and the 'Showing/Saying' Continuum. Pragmatics and Cognition 11, 39-91.

Winterstein, G. (2009). The Meaning of Too: Presupposition, Argumentation and Optionality. http://www.linguist.univ-paris-diderot.fr/ gwinterstein/docs/ WintersteinG-MeaningToo-Tbilisi.pdf 